\title{
Historicizar a experiência: ensaio sobre seus fundamentos teórico-metodológicos
}

\author{
Historicizing the experience: an essay on its theoretical and methodological foundations \\ Históricamente la experiencia: un ensayo sobre sus fundamentos teóricos y metodológicos
}

Recebido: 14/03/2021 | Revisado: 20/03/2021 | Aceito: 24/03/2021 | Publicado: 01/04/2021

\author{
Cecilia Ángela Odetti \\ ORCID: https://orcid.org/0000-0001-6760-8764 \\ Universidade Nacional del Litoral, Argentina \\ E-mail: odetticecilia@gmail.com \\ Lívia Diana Rocha Magalhães \\ ORCID: https://orcid.org/0000-0003-0784-6749 \\ Universidade Estadual do Sudoeste da Bahia, Brasil \\ E-mail: 1rochamagalhaes@gmail.com \\ Lia Tiriba \\ ORCID: https://orcid.org/0000-0003-0117-4160 \\ Universidade Federal Fluminense, Brasil \\ E-mail: liatiriba@gmail.com
}

\begin{abstract}
Resumo
Neste ensaio teórico, nos aproximamos da discussão acerca da "historicização da experiência, a partir das preocupações teóricas e epistêmicas que foram surgindo no decorrer das nossas pesquisas. Retomamos as indagações sobre a categoria experiência como um "termo ausente", que desenvolvemos tomando Thompson (1981) como referência. Recompomos brevemente a discussão sobre memória e história em Halbwachs (2011) e revisitamos a formulação de "historización de lá experiência", sustentada por Aróstegui (2004). Depois, incorporamos autores clássicos e contemporâneos para ressaltar que as experiências vividas podem se constituir em importantes materiais para o estudo das implicações dos sujeitos na história, superada sua condição de "evidencias".
\end{abstract}

Palavras-chave: Experiência; Memória; Historicização; Fundamentos metodológicos.

\begin{abstract}
In this theoretical essay, we approach the discussion about the "historicization of experience, due to the theoretical and epistemic concerns that have emerged in the course of our research. We resume the questions about the experience category as an "absent term", which we developed using Thompson (1981) as a reference. We briefly recomposed the discussion on memory and history in Halbwachs (2011) and revisited the formulation of "historización de lá experiencia", supported by Aróstegui (2004). Then, we incorporated classic and contemporary authors to emphasize that the lived experiences can constitute important materials for the study of the subjects' implications in history, overcoming their condition of "evidence".
\end{abstract}

Keywords: Experience; Memory; Historicization; Methodological foundantions.

\section{Resumen}

En este ensayo teórico, abordamos la discusión sobre la "historización de la experiencia, a partir de las inquietudes teóricas y epistémicas que han surgido en el transcurso de nuestra investigación. Retomamos las preguntas sobre la categoría experiencia como un "término ausente", que desarrollamos tomando como referencia a Thompson (1981). Recuperamos brevemente la discusión sobre memoria e historia en Halbwachs (2011) y revisitamos la formulación de "historización de lá experiencia", sustentada por Aróstegui (2004). Luego, incorporamos autores clásicos y contemporáneos para resaltar que las experiencias vividas pueden constituirse en importantes insumos para el estudio de las implicaciones de los sujetos en la historia, superando su condición de "evidencias".

Palabras clave: Experiencia; Memoria; Historización; Fundamentos metodológicos.

\section{Introdução}

O que significa "historicizar a experiência"? Essa é uma questão que nos remete a duas outras categorias: história e experiência. Entre outras, podemos convocar uma terceira: a categoria memória, que nos parece especial para adensar a reflexão sobre fundamentos teórico-metodológicos de pesquisas que retomam ou reavivam experiências que foram vividas e transmitidas ao longo da história. Trata-se de uma pergunta que nos reporta a preocupações de natureza epistêmica e empírica. 
Inevitavelmente, nos conduz a pensar sobre a consciência latente ou manifesta de fenômenos políticos vinculados a processos sociais vividos por mulheres e homens, inscritos em lugares de natureza política, econômica, cultural, de reprodução da vida (Tiriba, 2019), e que, na dinâmica de dado tempo, continuam presentes por meio dos testemunhos de vida. Desse modo, significa dizer que vamos nos ancorar em fundamentos teórico-metodológicos para a pesquisa das experiências sociais, a partir de quem as vivenciou, como uma das condições do conhecimento historiográfico. Isso implica que estamos elegendo os distintos modos segundo os quais a história afeta uma ou várias experiências coletivas concretas.

O tema da historicização de experiências vividas refere-se ao debate das implicações dos sujeitos sociais em determinados acontecimentos e às consequências de sua participação direta em disputas, conflitos e tensões que estruturaram o passado. Quando falamos da permanência da experiência ao longo do tempo, nos referimos à sua transcendência, principalmente no presente. Trata-se de uma reflexão analítica, que coloca o conhecimento histórico sob o crivo da relação entre a história e os condicionamentos materiais e culturais de uma sociedade, o que significa que vamos precisar recorrer a perguntas concretas de índole empírica. De que sujeitos e experiências estamos falando? Quais são as experiências individuais e coletivas que desejamos trazer à superfície? Considerando as experiências inteligíveis que foram vividas, qual seria o relevo de sua incidência no nosso presente?

Há um segundo bloco de questões (que também poderia ser o primeiro) que poderíamos levantar: qual nosso entendimento de história? Por que podemos dizer que a memória é parte e substrato da história? Como se dá a relação entre história, memória e experiência? Enfim, quais são os fundamentos teórico-metodológicos que precisamos mobilizar para "historicizar a experiência"?

Nosso intuito é instigar a discussão de caráter teórico-metodológico sobre as chamadas experiências vividas e transmitidas como objeto ou fonte de estudo. Tomamos como base as contribuições de autores de diferentes vertentes teóricas para explicitar que a categoria experiência, em sua historicidade, exige nossa atenção como pesquisadores, quer do campo de estudos em história, memória, trabalho e educação, quer de outros campos do conhecimento.

O ensaio está organizado em três partes. Na primeira parte, recuperamos a discussão sobre os diversos significados que o termo "experiência" assume em pesquisas sobre história, memória, trabalho e educação. Em particular, elegemos E. P. Thompson como principal interlocutor para indagar a possível ausência ou invisibilidade da experiência como objeto empírico e fundamento epistemológico das pesquisas em história, memória, trabalho e educação; na segunda parte, abordamos as matrizes teóricas que aportam contribuições para a discussão sobre memória e experiência, como marco de referência para "historicizar a experiência"; por fim, na terceira parte, ressaltamos a inevitabilidade de discutir tal abordagem pensando nas condições gerais de produção da consciência social. De acordo com a finalidade do presente ensaio, ainda há muitas questões em aberto nessa discussão e muitas indagações de ordem teórica e metodológica para serem mobilizadas e, consequentemente, consolidadas.

\section{Metodologia}

Neste texto, apresentado à guisa de "ensaio teórico", ou seja, um gênero discursivo em que o pensamento flui livremente, queremos deixar em aberto diversas questões e apresentar novas perguntas (Cândido, 1981; Portella, 2000; Larossa, 2003). Desde já, ressaltamos que, embora o escopo do texto não permita nos remeter a essa ou aquela experiência histórica, compartilhamos dos preceitos de E.P. Thompson no que diz respeito à necessidade de promover o diálogo disciplinado entre conceito e evidência interrogada, diálogo esse "conduzido por hipóteses sucessivas, de um lado, e a pesquisa empírica, de outro" (Thompson, 1981, pp. 49). Entre os autores, recorremos a Aróstegui (2004), sobretudo acerca de sua formulação sobre "historicização da experiência", e a Maurice Halbwachs (2011), na sua contribuição sobre a distinção entre memória e história. Em outras palavras, buscamos apoio em diferentes abordagens teóricas para entender a tessitura dos 
fundamentos teórico-metodológicos que implicam "historicizar a experiência". Devemos ressaltar que, de nossa parte, cremos não ser possível desconsiderar, em nenhum momento, que o processo de produção e percepção da experiência é indissociável das relações sociais, no tempo e lugar em que se estruturam.

\section{Resultados e Discussão}

\subsection{Experiência: o termo ausente?}

$\mathrm{Na}$ Argentina e no Brasil, assim como em outros países da América Latina, de certo modo, é bastante recente a discussão acerca da maneira como os pesquisadores tomam a experiência vivida, ora como parte integrante, ora como elemento para compreender determinados acontecimentos históricos. No Brasil, em particular, tivemos a oportunidade de elaborar um mapeamento de pesquisas no campo de história, trabalho e educação, que elegiam a experiência como fonte ou objeto de estudos e cujos pesquisadores se reportavam ao termo sem a preocupação de conceituá-lo, não raro sem fazer referência à sua matriz teórica. Em dado momento, considerando a experiência como "uma categoria que por mais imperfeita que seja, é indispensável ao historiador" (Thompson, 1981, pp. 15), nos perguntávamos em que medida a experiência constitui-se como um "termo ausente" entre os pesquisadores que buscam estabelecer relações entre história, memória, trabalho e educação. Na verdade, mesmo estando "presente" na produção acadêmica, quais os sentidos, significados e contribuições teóricometodológicas?

Nossos estudos permitem afirmar que a reconstituição da experiência de acontecimentos que afetaram e ainda afetam uma sociedade e, diretamente, determinados sujeitos sociais, transforma-os em testemunhas, fontes ou objetos de estudo.

Tais estudos recebem a atenção dos pesquisadores de várias ciências, considerando a possibilidade poliédrica de sua visibilidade em dimensões psicológicas, sociológicas, históricas, culturais e educacionais, entre outras. Todavia, quando se trata da sua recuperação como substrato para o conhecimento histórico, ainda há muitos questionamentos acerca da sua idoneidade epistemológica. Não é algo sem fundamento, pois, em geral, essas experiências, como expressão da agência humana individual e coletiva (Thompson, 1981), são tomadas com certa autonomia em relação à totalidade social, onde, em determinado espaço e tempo histórico, elas se constituem e são constituídas. Daí a importância de estudos que, interdisciplinarmente, possam contribuir para a compreensão do real como "síntese de muitas determinações, isto é, unidade do diverso" (Marx, 1978, pp. 116).

Nos estudos culturais, por exemplo, acreditamos ser insuficiente eleger E. P. Thompson como principal interlocutor se destituirmos o fundamento maior do pensamento do historiador inglês: o materialismo histórico-dialético. De acordo com a concepção materialista da história, ao contrário do idealismo, a cultura só pode ser entendida se "situada no lugar material que lhe corresponde" (Thompson, 1998, pp. 17). A compreensão de estrutura e superestrutura como pares dialéticos e, portanto, dos nexos indissociáveis entre economia e cultura, é condição sine qua non para a apreensão da experiência vivida, herdada e transmitida, entendida como termo médio entre ser social e consciência social (Thompson, 1981). Afinal, o que é o ser social senão o ser real, de carne e osso? O que é o ser social, senão expressão, parte constitutiva e, ao mesmo tempo, constituinte das condições objetivas/subjetivas de dado espaço/tempo histórico onde a experiência se realiza, é vivida e percebida?

Contrário ao reducionismo econômico e à "definição particular e limitada do econômico", Thompson (1981, pp. 190) parte da premissa de que existe um "processo histórico estruturado". Acredita ser "essencial manter presente no espírito o fato de os fenômenos sociais e culturais não estarem 'a reboque', seguindo os fenômenos econômicos a distância: eles estão em seu surgimento, presos na mesma rede de relações" (Thompson, 2001, pp. 208). Nessa perspectiva, a categoria cultura deve ser considerada como um "termo de junção", necessário para análise da experiência gerada na vida material e estruturado em termos de classe. Afirmar que a classe é uma formação, tanto econômica, quanto cultural, e que a luta de classes é sempre luta por valores (Thompson, 1987, 1981) encontra base empírica no fato de que, nos processos de luta, homens e mulheres 
[...] também experimentam sua experiência como sentimento e lidam com esses sentimentos na cultura, como normas, como obrigações familiares e de parentesco, e reciprocidades, como valores ou (através de formas mais elaboradas) na arte ou nas convicções religiosas. Essa metade da cultura (e é uma metade completa) pode ser descrita como consciência afetiva e moral (Thompson, 1981, pp.193).

Como Thompson, acreditamos que as pessoas não apenas reproduzem experiências e as introjetam em sua consciência; as experiências vividas e transmitidas pela memória histórica produzem:

[...] mudanças no ser social que dão origem à experiência modificada; essa experiência é determinante, no sentido de que exerce pressões sobre a consciência social existente, propõe novas questões e proporciona grande parte do material sobre o qual se desenvolvem os exercícios intelectuais mais elaborados (Thompson, 1981, pp. 16).

A categoria experiência, conforme Thompson, confere-nos a possibilidade de tomá-la, do ponto de vista epistemológico, como suporte empírico para analisar as formas de resistência e de luta de homens e mulheres, ao longo do largo processo de fazer-se como sujeito-individual-coletivo. No prefácio ao livro Experiência: o termo ausente? Sobre história, memória, trabalho e educação (Magalhães \& Tiriba, 2018), Gaudêncio Frigotto interpela os autores com questões que dizem respeito às consequências políticas da quase ausência da categoria experiência em nossas pesquisas e, com isso, a pouca acuidade para entender a realidade social:

[...] se a experiência está ligada aos processos da vida no trabalho, na educação, na política, na cultura humana em geral, o que explica a sua ausência ou a pouca frequência nas análises da relação trabalho e educação e movimentos sociais? A questão subjacente: quais as consequências políticas na luta de classe da ausência ou parca frequência da análise do terreno contraditório da experiência na compreensão do fato de que a maioria dos trabalhadores que pertencem à classe trabalhadora, mas não tem a consciência de seu pertencimento? (pp. 09)

Conforme Magalhães e Tiriba (2018, pp. 25), como experiência histórica e socialmente determinada, "a experiência individual é sempre experiência coletiva, gerada e geradora de memória coletiva”, o que nos remete à categoria memória como mais do que um termo de junção necessário para o desafio a que nos propusemos neste artigo: reunir alguns elementos teóricometodológicos que nos permitam "historicizar a experiência".

\subsection{Experiência, memória e história: Maurice Halbwachs e Julio Aróstegui}

Halbwachs (2011), para distinguir memória de história, parte de uma visão tradicional da história, ou seja, conhecimento elaborado acerca do passado, além de crônica épica dos grandes feitos de uma época ou construção selecionada e organizada, racionalmente, de experiências passadas (de acordo com os interesses de uma nação). Esse autor define memória como experiência vivida do acontecimento de dada realidade experimentada por grupos sociais. Em seu intento de discutir a noção de tempo do ponto de vista sociológico, diferencia o tempo da experiência na história do tempo da experiência na memória. A primeira é entendida como o registro de acontecimentos vividos por sociedades dentro de um tempo conjuntural, que marcou uma época. Já a segunda é considerada como registro de múltiplas experiências vividas dentro desse ou outro tempo, uma vez que permanecem na consciência do grupo que as recebeu diretamente, por meio da transmissão social, perdurando para além de seu tempo de origem. O autor sugere que uma experiência, a memória coletiva, só alcança a realidade de um acontecimento histórico quando tem força para marcar uma época.

Em síntese, para Halbwachs (2011), à luz do estudo sociológico da memória, a experiência vivida dura de acordo com a dinâmica, os interesses e a necessidade de um ou mais grupos sociais no presente, enquanto a história registra de forma elaborada o acontecimento passado, um registro temporal, localizado, de experiências políticas vividas por uma nação ou um povo. 
Feitas essas primeiras observações, passamos a conduzir a discussão com base na perspectiva apresentada, entre outros autores, por Aróstegui (2004), o qual afirma não haver história sem memória e que, embora sejam entidades distintas, é importante a apreensão de uma para a outra, sendo a memória tomada como fonte para a história, inclusive como veículo de transmissão. Porém, para que a memória social e coletiva das experiências seja o ponto de partida da discussão historiográfica, registra o autor, é preciso que se opere sua historicização. Assim, a memória social e coletiva da experiência é submetida à problematização do contexto de sua produção, como deve ser feito com qualquer objeto e fonte de estudo.

Conforme preconiza Aróstegui (2004), a historicização da experiência é identificada com a forma cultural da experiência vivida e está ligada ao sentido etimológico de história. Em grego, significa o que, em alemão, eles chamam de experiência (Koselleck, 2001). Assim, é possível afirmar como expressões semelhantes: "faça história" e "faça experiência".

É mister esclarecer que o tempo comum histórico não é unívoco nem unidimensional; pelo contrário: em sua complexidade, pode ser conceituado segundo a diversidade dialética dos estratos que o compõem e, por sua vez, estruturam as experiências.

Como argumenta Aróstegui (2004) "es un neologismo que se diferencia de historiar la experiencia, ya que éste último hace referencia a contar una historia desde un oficio que manipula la materia. Mientras que historizar es una elaboración que produce una realidad simbólica y discursiva nueva, convierte en historia una experiencia vivida que no ha sido formalmente objeto de la Historia (2001, pp. 144)". A novidade é justamente quando a experiência vivida se torna "[..] história por obra mismo de quienes que la viven (2001, pp. 144)". Isso supõe que o caráter da historicização é como uma via de mão dupla, que engloba o subjetivo e o objetivo. Dessa forma, “(...) a experiência individual e coletiva, pessoal e de grupo, a vida vivida socialmente, adquire o status de uma história formalizada (...)” (2001, pp. 144).

Assim, há de se pensar em um regime de historicidade que conceitua dado tempo histórico, privilegiando a experiência como âncora para reativar o passado, a fim de recuperar o destaque das experiências sociais realizadas por coletivos em sua localização em certos grupos, em seus referenciais de lutas, confrontos e conflitos.

Para Aróstegui, essa formulação é crucial para as formas de compreensão, apreensão e tradução das memórias, por ser geradora de experiências que ocorreram no passado recente, cuja manifestação na história coetânea, tendo em vista a recuperação de questionamentos sobre o passado palpável, não pode continuar sendo construída por consensos que ignoram determinados sujeitos e experiências. Por isso, é preciso pensar a história associando-a à experiência em dado tempo e espaço como condições para a produção da memória.

Essas concepções colocam no centro de suas propostas o movimento histórico associado à experiência humana, à ação e à capacidade de interação dos agentes que reconstroem e vivem o tempo em diferentes estratos e que são capazes de ligar o presente às condições do passado e às possibilidades de futuro. Tais argumentos levam a entender o presente como o tempo real da história (Koselleck, 2001; Aróstegui, 2004).

Consequentemente, historicizar a experiência e, por sua vez, apreender os movimentos da memória são atividades intelectuais baseadas no raciocínio crítico (Jablonka, 2016), que tem como ponto de partida as questões geradas desde o próprio presente daqueles que se propõem a investigar. É a historicização, portanto, sempre um conhecimento indireto do passado, através de traços que serão reconstruídos.

A própria experiência é o fundamento da historicização, pois a ideia de experiência está ligada à forma de sua recuperação, constituindo uma ação mediadora entre o que os homens fazem e sua capacidade de refletir sobre o que fazem. Tendo Thompson como referência, Aróstegui (2004, pp. 150) alerta que “(...) la creación de la conciencia es, igualmente el resultado de la acción, toda acción histórica crea conciencia histórica, un paso extremadamente ligado con lo que aquí llamamos la historización de la experiencia (...)"

Da mesma forma, a memória desempenha um papel decisivo na experiência como suporte para a percepção da 
temporalidade, onde o que foi vivido e herdado está em jogo. Por esse motivo, sem a capacidade de lembrar - socialmente assegurada pela transmissão de geração a geração, em suas continuidades e rupturas - não é possível apreender o presente como história, ou seja, historicizar a experiência que se baseia, por sua vez, na historicização da memória.

[...] La memoria no es la historia, hemos dicho, pero de la misma que la memoria es un presupuesto de la historia, recíprocamente la historia dota de sentido y referencia a la memoria, la contextualiza y la rectifica si es preciso, la coloca dentro de un orden de realidades y de conocimientos que trascienden al individuo (...) (Aróstegui, 2004, pp. 184).

Nessa perspectiva, historicizar a experiência é uma maneira de objetivar a memória, um trabalho mobilizado com base nas necessidades de um presente histórico, que se reposiciona de acordo com determinados interesses sociais, políticos, culturais. Nesse sentido, falar de experiências ou de memória de experiências vividas para o conhecimento da realidade supõe que não há experiências sociais que sejam neutras. Ora, há visões de mundo assimiladas nesse processo que não têm apenas valor gnosiológico, mas que são componentes de disputa ou de luta de sentidos na história.

\subsection{História, memória e a experiência: recuperando nosso lugar na discussão}

Não é novidade a discussão sobre a natureza da consciência social das experiências que fundamentam o conhecimento histórico da realidade social. Recordamos que Marx e Engels (1988), concebendo a prática social do trabalho, uma força real do capital, esboçam uma análise sobre como a sociedade capitalista cria "falsa consciência", ao enfocar a realidade em sua aparência, e não em sua essência. Entendem a dominação como processo inteligível que penetra na essência do ser social, transformando-o em coisa, em uma consciência alienada.

E aqui não é nosso intuito discutir história e consciência de classe, como expressara, por exemplo, Lukács (1974), mas colocar em evidência que tomar as experiências protagonizadas por dados sujeitos na história supõe localizá-las a partir das condições em que foi construída e o lugar dos sujeitos sociais que a vivenciaram. A depender do lugar ocupado por esses sujeitos nessas experiências, os seus testemunhos vivos ou representados podem apresentar conteúdos escondidos, aparentemente neutros, mas que estão presentes na memória coletiva e são necessários para as forças produtivas dominantes na história. Assim, há muitas memórias de experiências históricas vividas e transmitidas por indivíduos representantes de dados grupos sociais, instituições e visões de mundo. Contudo, o que devemos constituir como objeto de atenção é a maneira como essa experiência foi ou tem sido apropriada na produção e reprodução da realidade.

Retomando nossas preocupações, precisamos discutir por que estamos elegendo ou por que elegemos determinadas experiências para desvendar sua tessitura histórica e tratá-las com o mesmo rigor que utilizamos com outras fontes históricas. E enquanto tal, devem ser incialmente tomadas apenas como "evidências", que precisam ser recuperadas, cotejadas e analisadas.

Desde o enfoque do materialismo histórico, que pondera relacionalmente as condições materiais de existência da capacidade humana prática - entendida como práxis -, é possível captar o movimento dialético da temporalidade da existência em termos concretos, processo que supõe a apreensão ou apropriação do objeto pela captação ou registro ativo do sujeito.

Se é na história que se opera a disputa da consciência social, falar de historicização da experiência significa falar sobre sua recuperação à luz dos processos sociais e históricos fulcrais; ou seja, há de se levar em conta a realidade social, a história de homens e mulheres reais, que vivenciaram, deixaram, transmitiram, operaram a apreensão de um acontecimento histórico, atravessado por interesses coletivos.

Seguindo essa linha de raciocínio, experiência, memória e história estão dialeticamente relacionadas em sua constituição ontológica, que respeita sua própria evolução em várias direções, sem perder a identidade de cada uma. Como unidade de múltiplas determinações (Marx, 1978), podem manifestar relações complementares e contraditórias: “(...) las 
memorias individuales y colectivas son un insumo del historiador y al mismo tiempo son parte activa de las configuraciones sociales donde se producen sentidos, porque componen los marcos imaginarios con los que se orientan los agentes (...)" (Alonso, 2014, pp. 10).

Tal exercício exige abordar os processos de memória e história de maneira integrativa, retornando à concepção de totalidade do pensamento marxista (Alonso, 2015). A abordagem totalizante é relacional e baseada nas possíveis ligações de um conjunto dialeticamente interconectado. Como tal, é considerado epistemologicamente necessário avançar o processo de conhecimento, partindo de abstrações sucessivas em constante conexão com a realidade existente, diferenciando-se das afirmações gerais que obscurecem as relações do particular.

Assim, sob certas condições de produção da vida, constroem-se categorias simples que não são formas que controlam tudo, mas dão sentido a tudo e até ao que é constituído à margem. Em síntese, a totalização se manifesta

[...] como un momento necesario, pero a la vez provisorio en el proceso de producción social de conocimiento. Y esa constante secuencia dialéctica de totalización/destotalización/retotalización sería lo que permitiría deconstruir los conocimientos establecidos en la perspectiva de una construcción futura, temporal y limitada ella misma, pero paso indispensable para la comprensión y la acción. (Alonso, 2015, pp. 191)

Colocar em evidência a natureza social e coletiva das experiências constitutivas de visões de mundo pode nos conduzir a analisar a história na relação dialética entre parte e todo, num movimento que nos permite ver como muitas experiências - na sua relação individual e coletiva - podem ter se tornado construtoras de aprendizagens éticas, culturais e políticas, que estão processualmente moldando nossas sociedades.

\section{Considerações Finais}

Neste ensaio, ressaltamos que as experiências compartilhadas por determinados sujeitos sociais na história do próprio tempo - e que são convertidas em objeto de estudo historiográfico - antes de mais nada pressupõem a necessidade de colocálas sob o crivo da sua historicização. Essa é uma das preocupações que temos tido todas as vezes que vamos discutir a experiência, mais especificamente a memória da experiência em sua amplitude de práxis social, na dialética do passado, presente e futuro.

E assim, nos valendo da observação de Hobsbawm (1992), lembramos que nosso intento não é falar do lugar da chamada "história do presente", mas ressalvar sua contribuição para pensar a tensão entre a experiência vivida, memória e transmissão ou recuperação historiográfica para o entendimento dos processos sociais.

Todos nosotros, inevitablemente, escribimos la historia de nuestro propio tiempo cuando miramos el pasado y, en cierta medida, emprendemos las batallas de hoy con el vestuario de la época. Pero aquellos que sólo escriben la historia de su propio tiempo no pueden entender el pasado y lo que vino de él. Incluso pueden falsificar el pasado y el presente, sin tener la intención de hacerlo (pp. 15-16).

O exercício de historicizar a experiência recompõe o lugar de quem faz, de quem constrói o relato de experiências coletivas compartilhadas e sua continuidade dialética. Trata-se, portanto, de compreender a memória na história. Na perspectiva da história vista de baixo, Thompson $(1981,1998)$ sugere que construir o conhecimento histórico crítico da "experiência" significa recuperar o papel dos sujeitos como construtores da história, sua capacidade de colocar em evidência aspectos obscuros, pouco estudados ou, mesmo, inviabilizados pelas classes dominantes.

Tomar a experiência em sua historicização significa estudá-la por meio de um método que possibilite a visibilidade de seus marcos fundantes, identificadores de dado tempo histórico e dos diferentes estágios sociopolíticos que os conduzem, 
dialeticamente, ao tempo presente. Nessa esteira, compreendemos que, para que a experiência vivida seja analisada como objeto ou fonte do conhecimento da realidade social, é necessário que sua evidência seja interrogada e historicizada. Sendo assim, a questão é saber quais perguntas fazemos ao objeto (no caso, as experiências vividas, herdadas e transmitidas), de maneira a compreendê-lo como totalidade social.

Discutir, realizar perguntas acerca do processo de historicização da experiência, como necessidade de perscrutar o contexto contemporâneo e presente, tanto social, como político, é um exercício que tem exigido de todas nós o estudo de diversas concepções teórico-metodológicas de história e memória. Essas concepções nos encaminham para o entendimento, com menor ou maior densidade, de experiências passadas que foram ressaltadas ou negadas, silenciadas, obscurecidas e que afetam uma sociedade e uma cultura, constituindo-se como matéria viva da história da educação e do trabalho. É nessa perspectiva, que escrevemos este ensaio.

Tivemos como intenção abrir e instigar o debate epistemológico acerca do caráter histórico da experiência e da memória, o que requer o diálogo disciplinado entre a teoria até então acumulada e os elementos objetivos/subjetivos que apreendemos da realidade humano-social. Sem dúvida, outras pesquisas que, direta ou indiretamente tratem das relações dialéticas entre história, experiência e memória poderão ampliar o "estado da questão" e os fundamentos teóricometodológicos que dão suporte aos procedimentos de pesquisas que buscam interrogar evidencias de um dado fenômeno em estudo. $\mathrm{O}$ debate sobre os modos pelos quais temos buscado descortinar a dialogia passado, presente e futuro nos desafia como dever de ofício a realizar o diálogo interdidicplinar, exigido por nosso campo de atuação enquanto pesquisadores e educadores. Esperamos que trabalhos futuros estabeleçam novos olhares, recuperando e ampliando para alhures a discussão aqui tratada.

\section{Referências}

Alonso, L. (2014), “Acerca de la interpenetración de memoria e historia”, en sección Teoría Crítica - Retrospección en Centro de Estudios de Teoría Crítica, http://teoriacritica.com.ar/pdfs/interpenetr_memoria.pdf,.

Alonso, L. (2015), “Retorno de la totalización y método historiográfico”, en Actas de las 1ras. Jornadas Nacionales de Historiografía, Universidad Nacional de Río Cuarto, Río Cuarto, 2015.

Aróstegui, J. (2004), La historia vivida. Sobre la historia del presente, Madrid.

Cândido, A. (1981). O significado de Raízes do Brasil [Prefácio]. In: Buarque de Holanda, S. Raízes do Brasil. (14a ed.): José Olympio.

Frigotto, G. (2018), Prefacio in “Experiência O termo ausente?”. In: Magalhães, L. D. R.; Tiriba, L. (org.), Sobre história, memória, trabalho e Educação. Uberlândia, Navegando Publicações, pp. 05-12

Halbwachs, M. (2011), La memoria Colectiva, Traducción: F. Balcarce, Colección Estudios Durkheimnianos, Buenos Aires, Miño y Dávila.

Hobsbawn, E. (1992), Los Ecos de la Marsellesa, Editora Crítica.

Jablonka, I. (2016), La historia es una literatura contemporânea, Manifiesto por las ciencias sociales, Buenos Aires, Fondo de Cultura Económica.

Koselleck, R. (2001), Los estratos del tiempo: estudios sobre la historia, Barcelona.

Larossa, J. (2003). O ensaio e a escrita acadêmica. Educação e Realidade, Porto Alegre, 28(2), 101-115.

Lukács, G. (1974), História e Consciência de Classe: estudos de dialética marxista, Escorpião.

Magalhães, L. D. R., \& Tiriba, L. (2018), “Experiência O termo ausente?”. In L. D. R. Magalhães, L. Tiriba (eds.), Sobre história, memória, trabalho e educação, Uberlândia, Navegando Publicações, pp. 09-23

Marx, K. (1978), Introdução à crítica da economia política. In K. Marx, Manuscritos económicos filosóficos e outros textos escolhidos, São Paulo, Abril Cultural.

Marx, K., Engels, F. (1988), O Manifesto Comunista, Global.

Thompson, E. P. (1981), A miséria da teoria ou um planetário de erros, Zahar Editores.

Thompson, E. P. (1987), A Formação da classe operária inglesa, Paz e Terra.

Thompson, E. bP. (1998), Costumes em comum. Estudos sobre a cultura popular tradicional, Companhia das Letras. 
Research, Society and Development, v. 10, n. 4, e9810413882, 2021

(CC BY 4.0) | ISSN 2525-3409 | DOI: http://dx.doi.org/10.33448/rsd-v10i4.13882

Thompson, E. P. (2001), Folclore, antropologia e história social. In A.L. Negro, S. Silva, S. (eds.), A peculiaridade dos ingleses e outros artigos, Unicamp, pp 227-267.

Tiriba, L. (2019). Reprodução ampliada da vida: o que ela não é, parece ser e pode vir a ser. In: Almeida, J. R. M., \& Bertoni L. M. (org.). Estado, política e sociedade: está o mundo de ponta cabeça? Technopolitik, 69-89. 